Ágora Rev. Cient. 2019; 06(02):e1

\title{
Evaluación de la actividad anti-Candida albicans del aceite esencial de Clinopodium pulchellum (Kunth) Govaertz "panizara"
}

\author{
Evaluation of the anti-Candida albicans activity of the essential oil of Clinopodium pulchellum (Kunth) \\ Govaertz "panizara"
}

Edgar Robert Tapia Manrique ${ }^{1}$, Diego Alejandro Valdivieso Marquez ${ }^{1}$

\section{RESUMEN}

Objetivo: Evaluar la actividad anti-Candida albicans in vitro del aceite esencial de las hojas de Clinopodium pulchellum (Kunth) Govaerts "panizara". Materiales y Métodos: El material vegetal fue recolectado en el distrito de Huacaschuque, provincia de Pallasca, capital Cabana, región Ancash. El aceite esencial se obtuvo mediante un equipo de destilación por arrastre a vapor de agua, usando $5 \mathrm{~kg}$ de hojas frescas de panizara. La actividad in vitro anti-Candida albicans se realizó por el método de difusión en agar exponiendo actividad del aceite esencial a concentraciones de $100,75,50$ y $25 \%$ utilizando nistatina como control positivo. Resultados: El rendimiento del aceite esencial fue de $0,58 \% \mathrm{v} / \mathrm{p}$. En la determinación analítica de la actividad anti-Candida albicans, el aceite esencial al 100, 75, 50 y 25\% presentó una halo de inhibición de 25,233; 23,4; 21,433 y 16,2 mm respectivamente. Conclusión: El aceite esencial de las hojas de Clinopodium pulchellum (Kunth) Govaerts "panizara" posee actividad antifúngica significativa frente a la cepa de Candida albicans en concentraciones de 100, 75 y $50 \%$.

Palabras clave: aceite esencial, Clinopodium pulchellum, actividad antifúngica, Candida albicans.

\begin{abstract}
Objective: To evaluate the anti-Candida albicans activity in vitro of the essential oil of the "panizara" leaves. Materials and Methods: The vegetal material was collected in the district of Huacaschuque, province of Pallasca, region of Ancash. The essential oil was obtained by means of steam distillation equipment, using 5 $\mathrm{kg}$ of panizara leaves. The in vitro anti-Candida albicans activity was performed by the agar diffusion method exposing essential oil activity at concentrations of 100, 75 and 50\% using nystatin as a positive control. Results: The yield of the essential oil was $0.58 \% \mathrm{v} / \mathrm{p}$. In the analytical determination of the anti-Candida albicans activity, the essential oil at $100 ; 75 ; 50$ and $25 \%$ presented an inhibition halo of 25,233; 23.4; 21.433 and $16.2 \mathrm{~mm}$ respectively. Conclusion: The essential oil of the leaves of Clinopodium pulchellum (Kunth) Govaerts "panizara" has significant antifungal activity against the strain of Candida albicans in concentrations of 100, 75 and $50 \%$.
\end{abstract}

Keywords: essential oil, Clinopodium pulchellum, antifungal activity, Candida albicans.

${ }^{1}$ Universidad Nacional Mayor de San Marcos. Facultad de Farmacia y Bioquímica.

\section{INTRODUCCIÓN}

Durante los últimos años se ha incrementado la incidencia de enfermedades fúngicas (1) y el considerable aumento de pacientes inmunocomprometidos con quimioterapia, nutrición parenteral, cirugía de trasplante y el uso de agentes antimicrobianos de amplio espectro, quienes son altamente susceptibles a las infecciones oportunistas. Las infecciones fúngicas sistémicas y dérmicas son la causa de gran morbimortalidad en este tipo de pacientes (2).

Para la Organización Mundial de la Salud (OMS), la medicina tradicional y complementaria (MTC) es la suma de los conocimientos, habilidades y prácticas de diversas culturas, utilizadas para mantener la salud. Debido a esto se ha desarrollado una nueva estrategia de la 
Medicina Tradicional a fin de promover la utilización segura y eficaz de la MTC a través de la regulación y la investigación. Como respuesta a esto, el Perú ha efectuado importantes aportes de especies y variedades para el mundo. El empleo de los recursos vegetales viene incrementándose, debido al conocimiento de su composición química y a los ensayos farmacológicos realizados (3).

Las micosis causadas por especies del género Candida y especialmente por Candida albicans, ha aumentado en las últimas tres décadas. La zona más frecuentemente afectada son los pliegues cutáneos donde la humedad crea un hábitat adecuado para su supervivencia. Se puede manifestar como: intertrigo de grandes pliegues, erosión interdigital, candidiasis del pañal, foliculitis, onicomicosis candidiástica con parinoquia y perionixis (4).

Nuestro país reconocido como territorio megadiverso tiene una variada riqueza de suelos debido a las diversas zonas geográficas, factores edáficos $\mathrm{y}$ otros factores ambientales, que favorecen el desarrollo de un gran número de recursos vegetales con diversas propiedades terapéuticas, como la antifúngica. Las plantas aromáticas de la familia Lamiaceae son usadas en infusiones y han sido ampliamente estudiadas por sus propiedades antimicrobianas. Dentro de esta familia se encuentra el género Clinopodium, el cual ha sido objeto de diversas investigaciones acerca de la actividad antimicrobiana en aceites esenciales y en diversos extractos, sin embargo, no hay investigaciones reportados de la especie vegetal Clinopodium pulchellum (Kunth) Govaerts "panizara" con respecto al estudio de la actividad antifúngica frente a Candida albicans.

\section{MATERIALES Y MÉTODOS}

La investigación se realizó en el Instituto de Investigación en Ciencias Farmacéuticas y Recursos Naturales "Juan de Dios Guevara" de la UNMSM, el Instituto de Microbiología y Parasitología "Simón Pérez Alva" de la Facultad de Farmacia y Bioquímica de la UNMSM.

\section{Reactivos y Equipos}

Los reactivos utilizados fueron adquiridos de las casas comerciales Merck y Sigma: metanol, etanol, n-hexano, butanol, sulfato de sodio anhidro, agar Dextrosa Sabouraud, escala de Mac Farland, DMSO (dimetilsulfóxido). Por otro lado, se utilizaron equipos tales como: cámara de incubación Memmert, estufa y destilador por arrastre a vapor de agua.

\section{Colecta de la muestra}

Hojas frescas de Clinopodium pulchellum (Kunth) Govaerts "panizara" fueron recolectadas en el distrito de Huacaschuque, provincia de Pallasca, capital Cabana, Región Ancash ubicada a $3100 \mathrm{msnm}$, durante el mes de diciembre del 2017; las hojas se secaron bajo sombra a temperatura ambiente promedio $20{ }^{\circ} \mathrm{C}$ durante ocho días. La clasificación taxonómica se realizó en el Museo de Historia Natural de la UNMSM.

\section{Obtención del aceite esencial}

Cinco kilogramos de hojas secas fueron tratados en un equipo destilación por arrastre de vapor de agua. El destilado se separó tomando en cuenta sus propiedades de inmiscibilidad y diferencia de densidades entre el agua y el aceite esencial, se deshidrató con sulfato de sodio anhidro y posteriormente se conservó en un frasco de vidrio de color ámbar bajo refrigeración a una temperatura de $4^{\circ} \mathrm{C}(13,14)$.

\section{Determinaciones antifúngicas}

En la determinación de la actividad antifúngica frente a Candida albicans, se empleó el método de difusión en Agar. Esta prueba se basa en la inhibición del crecimiento fúngico, mediante la difusión de las sustancias activas en un medio sólido y se evidencia por la formación de halos claros alrededor de las colonias (5).

\section{Microorganismo}

Candida albicans ATCC 10231, del Laboratorio de Microbiología del Instituto de Química Biológica, Microbiología y Biotecnología "Marco Antonio Garrido Malo" de la Facultad de Farmacia y Bioquímica, UNMSM.

\section{Muestra}

Aceite esencial de las hojas de Clinopodium pulchellum (Kunth) Govaerts "panizara" en concentraciones de $100 ; 75 ; 50$ y 25 por ciento, utilizando como diluyente alcohol etílico de $96^{\circ}$.

\section{Preparación del inóculo}

Para la preparación de la suspensión del inóculo, se utilizó a la Candida albicans crecidos en agar dextrosa Sabouraud por $48 \mathrm{~h}$. Luego se suspende al microorganismo en solución salina $0,85 \%$ estéril y se ajusta la turbidez al equivalente al tubo 0,5 de la escala de McFarland.

\section{Preparación e inoculación de las placas}

El medio agar dextrosa de Sabouraud previamente reconstituido, esterilizado, enfriado y mantenido a $45^{\circ} \mathrm{C}$, se procedió a inocular con 1 $\mathrm{mL}$ de suspensión del inóculo $\left(1 \times 10^{6} \mathrm{UFC} / \mathrm{mL}\right)$ 
por cada $100 \mathrm{~mL}$ de medio de cultivo, homogenizado y distribuido en placas Petri de vidrio estéril de $90 \mathrm{~mm}$ de diámetro. Se dejó solidificar y se rotuló con el nombre del microorganismo. Finalmente se hacieron pozos con la ayuda de un sacabocado de acero de $11 \mathrm{~mm}$ de diámetro externo, en cada placa se hizo 2 ó 3 pozos equidistantes.

\section{Inoculación e incubación de la muestra}

Se procedió a colocar $100 \mu \mathrm{L}$ del aceite esencial en las concentraciones señaladas anteriormente en los pozos, se dejó reposar por 30 minutos a temperatura ambiente y se lleva a incubación a $37^{\circ} \mathrm{C}$ por 24 horas. Como control negativo se utilizó etanol $96^{\circ}$ y como control positivo se utilizaron discos de susceptibilidad con nistatina $0,2 \mu \mathrm{g}$.

\section{Lectura e interpretación de los resultados}

Se observaron las zonas claras de inhibición del crecimiento (halos) y se midió los diámetros en $\mathrm{mm}$. Se considera que tiene una actividad antifúngica significativa a un halo de inhibición mayor a $18 \mathrm{~mm}$.

\section{RESULTADOS}

Los resultados del presente trabajo se muestran en las Tablas 1, 2 y Figura 1, respectivamente.

Tabla 1. Análisis preliminar y constantes físicas de Clinopodium pulchellum (Kunth) Govaerts "panizara"

\begin{tabular}{|c|c|}
\hline DETERMINACIONES & RESULTADOS \\
\hline Análisis organoléptico & $\begin{array}{l}\text { Líquido oleoso, } \\
\text { ligeramente amarillo, } \\
\text { aromático, agradable y } \\
\text { altamente volátil }\end{array}$ \\
\hline Solubilidad & $\begin{array}{l}\text { Insoluble en agua, } \\
\text { ligeramente soluble en } \\
\text { metanol, soluble en etanol, } \\
\text { n-hexano y éter etílico. }\end{array}$ \\
\hline Constantes físicas* & $\begin{array}{c}\text { Densidad }\left(21^{\circ} \mathrm{C}\right): \\
0,978 \pm 0,018 \\
\mathrm{pH}\left(21^{\circ} \mathrm{C}\right): 5,60 \pm 0,004 \\
\text { Índice de refracción } \\
\left(21^{\circ} \mathrm{C}\right): 1,475 \pm 0,011\end{array}$ \\
\hline
\end{tabular}

Tabla 2. Resultados de la actividad antifúngica del aceite esencial de Clinopodium pulchellum (Kunth) Govaerts "panizara" frente a Candida albicans empleando el método de difusión en agar

\begin{tabular}{|l|c|c|}
\hline \multirow{2}{*}{ Muestra } & $\begin{array}{c}\text { Concentración del aceite } \\
\text { esencial diluido en etanol } \\
\text { absoluto (v/v) }\end{array}$ & $\begin{array}{c}\text { Candida albicans } \\
\text { (halos de inhibición en } \\
\text { mm) }\end{array}$ \\
\hline $\begin{array}{l}\text { Aceite esencial de } \\
\text { Panizara* }\end{array}$ & $100 \%$ & $25,233 \pm 0,252$ \\
\cline { 2 - 3 } & $75 \%$ & $23,400 \pm 0,458$ \\
\cline { 2 - 3 } & $50 \%$ & $21,433 \pm 0,153$ \\
\hline $\begin{array}{l}\text { Control positivo } \\
\text { (Nistatina) }\end{array}$ & $25 \%$ & $16,200 \pm 0,529$ \\
\hline Control negativo & $0,2 \mu \mathrm{g} / \mathrm{mL}^{* *}$ & $38,330 \pm 0,404$ \\
\hline
\end{tabular}

*El aceite esencial se diluyó en etanol absoluto.

$* * 0,2 \mu \mathrm{g}$ de nistatina por cada $\mathrm{mL}$ de etanol absoluto.
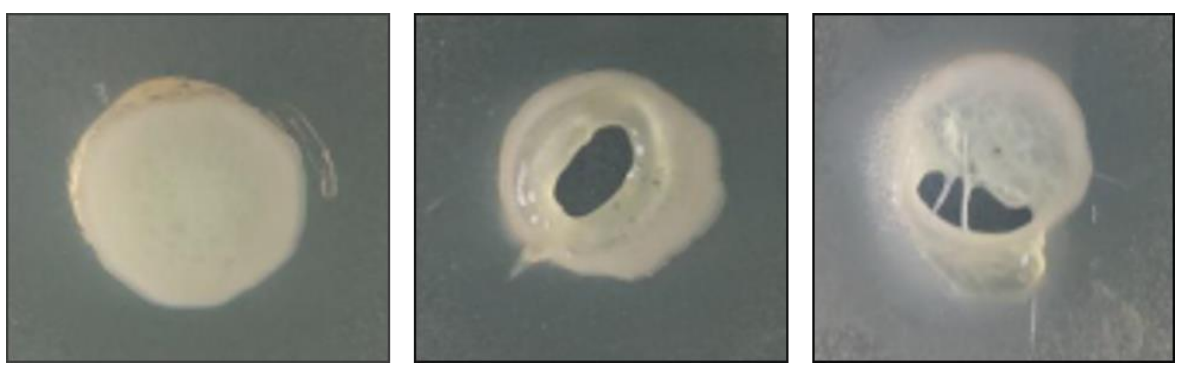

Fig. 1. Halos de inhibición producidos por el aceite esencial al 50, 75 y $100 \%$ respectivamente de izquierda a derecha. 


\section{DISCUSIÓN}

El aceite esencial de Clinopodium pulchellum (Kunth) Govaerts "panizara" presentó un rendimiento de $0,58 \% \mathrm{v} / \mathrm{p}$ a partir de $5 \mathrm{~kg}$ de hojas, mientras que otra investigación reportó un rendimiento mayor, equivalente al $1 \%$, aunque la diferencia se debió a factores ecológicos, climáticos y edafológicos, la principal diferencia radicaría en el tratamiento de la muestra, ya que la investigación de Carhuapoma tuvo como referencia el uso de hojas secas $(5,6)$.

En diversas investigaciones se establece que la acción antimicrobiana de los componentes de los extractos y de los aceites esenciales se debe al carácter lipofílico de su esqueleto de hidrocarbonos y principalmente al carácter hidrofílico de sus grupos funcionales (7). El linalool, posee grupo funcional alcohol, es un antimicrobiano moderado, estomacal y carminativo (8).

Se ha demostrado que el aceite esencial de Clinopodium pulchellum (Kunth) Govaerts "panizara" posee actividad significativa frente a Candida albicans en las concentraciones de 50\%, $75 \%$ y $100 \%$ que equivalen a $48,9 \mathrm{mg} ; 73,35 \mathrm{mg}$; $97,8 \mathrm{mg}$ respectivamente de aceite esencial de panizara frente a la cepa de Candida albicans. Para el control positivo se trabajó a concentración de $0,2 \mu \mathrm{g} / \mathrm{mL}$ de nistatina. Esta actividad podría atribuirse a la presencia de ciertos terpenos presentes en su composición química (9), debido a que los terpenoides son los principales constituyentes de la actividad antimicrobiana de los aceites esenciales (10), siguiendo en orden de actividad los terpenoides que contienen grupos fenoles $\mathrm{y}$ alcoholes, luego los que poseen aldehídos y por último los que tienen grupos cetónicos, aunque mecanismo específico de los terpenoides aún no ha sido claramente caracterizado. Actualmente se propone como posible sitio de acción, la membrana celular donde los terpenoides surtirían efecto, desencadenando una serie de procesos que podrían arribar en la muerte microbiana $(11,12)$. En este caso el linalool, D-limoneno, terpinen-4-ol, gammaterpineno, eucaliptol, presentes en la composición química del aceite esencial de panizara actuarían en sinergismo.

\section{CONCLUSIONES}

El aceite esencial de Clinopodium pulchellum (Kunth) Govaerts "panizara" presenta actividad antifúngica significativa frente a Candida albicans en las concentraciones de 50\%, 75\% y $100 \%$.

\section{AUTOR DE CORRESPONDENCIA}

Dr. QF. Edgar Robert Tapia Manrique

Facultad de Farmacia y Bioquímica

Universidad Nacional Mayor de San Marcos

E-mail: edgar_tapia1706@hotmail.com

\section{REFERENCIAS BIBLIOGRÁFICAS}

1. Navarro VM, Gonzalez A, Fuentes M, Aviles M, Rios MY, Zepeda G, Rojas MG. Antifungal activites of nine traditional Mexican medicinal plants. J Ethnopharmacol. 2003;87(1):85-88.

2. Lopez SN, Castelli MV, Zacchino SA, Dominguez JN, Lobo G, Charris- Charris J, Cortes JC, Ribas JC, Devia C, Rodriguez AM, Enriz RD. In vitro antifungal evaluation and structure-activity relationships of a new series of chalcone derivatives and synthetic analogues, with inhibitory properties against polymers of the fungal cell wall. Bioorg Med Chem. 2001;9(8):1999-2013.

3. Estrategia de la OMS sobre medicina tradicional 2014-2023.OMS ,2013.

4. Kim J, Sudbery P. Candida albicans, a major human fungal pathogen. J Microbiol. 2011;49(2):171-177.

5. Rojas R, Bustamante B, Bauer J, Fernandez I, Alban J, Lock O. Antimicrobial activity of select Peruvian medicinal plants. Journal of Pharmacology. 2003; 88(2-3): 199-2004.

6. Carhuapoma M, López S, Veliz F, Inostrosa L, Yuli R, Carlos N. Composición química, actividad antioxidante y toxicidad aguda del aceite esencial de Saturaje pulchella "panizara". Theorema UNMSM. 2014;(1):5763

7. Crop \& Food Research. Essential oils and their production. New Zealand, Institute for Crop \& Food Research Institute. 2001. Disponible en: http://www.crop:cri.nz/home/productsservice s/publications/broadsheet s/039essentialoils.pdf

8. Kalemba D, Kunicka A. Antibacterial and antifungal properties of essential oils. Current Medicinal chemistry. 2003;10(10): 813-829

9. Kuklinski, C. Farmacognosia. Estudio de las drogas y sustancias medicamentosas de origen natural. Edit. Omega. Barcelona;2003.

10. Rodrigues F, Colares A, Nonato C, GalvãoRodrigues F, Mota M, Moraes Braga $\mathrm{M}$ et al. In vitro antimicrobial activity of the essential oil from Vanillosmopsis arborea Barker (Asteraceae) and its major constituent, $\alpha$ bisabolol. Microbial Pathogenesis. 2018;125(1):144-149. 
11. Kumari S, Pundhir S, Priya P, Jeena G, Punetha A, Chawla K et al. EssOilDB: a database of essential oils reflecting terpene composition and variability in the plant kingdom. Database. 2014;2014(1):1-12.

12.Prakash A, Baskaran R, Paramasivam N, Vadivel V. Essential oil based nanoemulsions to improve the microbial quality of minimally processed fruits and vegetables: A review. Food Research International. 2018;111(1):509-523.

13. Alam M, Bristi N, Rafiquzzaman M. Review on in vivo and in vitro methods evaluation of antioxidant activity. Saudi Pharmaceutical Journal. 2013;21(2):143-152.

14.Bruneton J. Farmaconogsia. Fitoquímica. Plantas medicinales, 2da. Edicion. ZaragozaEspaña: Acribia S.A. 2001.

15. Castro, A. Composición química del aceite esencial de las hojas de Erythroxylum novogranatense (Morris) “coca”. 2008. Tesis para optar al Grado de Doctor en Farmacia y Bioquímica. UNMSM, Lima. 